Environment Conservation Journal 15(3)55-62, 2014

ISSN 0972-3099 (Print) 2278-5124 (Online)

Abstracted and Indexed

\title{
An ecological assessment of vineyard houses: a case study from Bucak
}

\author{
Hacer Mutlu Danaci
}

Received:09.03.2014

Revised:20.08.2014

Accepted:15.09.2014

\begin{abstract}
Within cultural landscapes, there exists vernacular architecture that is characteristic in design of its region, construction techniques and materials, but is currently rarely used. Anatolia, a region that encompasses various regions with differing climates and cultures, is considerably rich in architectural splendor. In Southern Turkey, a part of Anatolia, vineyard houses in the Mediterranean Region's Bucak Borough of Burdur Province are prototypical authentic vernacular architecture samples. Vineyard House use is becoming obsolete and these structures are disappearing. These vineyard houses are a cornerstone of the culture that built them, yet they have not attracted sufficient attraction in literature. Examination of sample relief works of vineyard houses within the borders of Bucak Borough placed their importance in an ecological context. Our goal is to ultimately protect these structures for both planning principles and to preserve the material, construction technique and cultural landscape to make vineyard houses usable to summer vacationists coming from the Antalya Province. This study is to ensure the vernacular architecture of vineyard houses in Bucak, they do not have any official protection status, are processed into literature, and to be a guide to any new designs. Vineyard houses' have ecological properties in the framework of ecological criteria encompassing regional architecture, settlement structure, building form, place organization, and material choice.
\end{abstract}

Keywords: Bucak, cultural landscape, vernacular architecture, vineyard houses

\section{Introduction}

Vernacular architecture is a required staple in supplementing cultural landscapes. Structures constructed from natural materials and endemic construction techniques are considered in this scope (Bowyer, 1980; Oliver, 2003; Vellinga et al. 2007 and Mutlu Danac1, 2012). Regional architecture has inherent variability based on a region's culture and environment. Vineyard houses are quintessential examples of native, regional Anatolian architecture, but are unfortunately growing obsolete.Vineyard houses are plain residences in close proximity to permanent settlements in Anatolia. They are also used as summer resorts due to suitable climate conditions and proximity to fruit-producing gardens. Vineyard houses are comprised of bottom floor depots, open halls (balconies) on the upper floors, and rooms with living areas. A main purpose of their location was to allow comfortable transport of produce between houses and gardens

Author's Address

${ }^{1}$ Akdeniz University, FFA, Architectural Department, Dumlupinar Boulevard, Campus, 07058, Antalya

E-mail:hacermutlu@gmail.com
(Mutlu Danaci, 2012). As in other regions of Anatolia, there are also temporary settlement locations in the Mediterranean Region's Bucak Borough of Burdur Province during summer months. Contrasting from settlements surrounded on three sides by mountains in the borough's center, vineyard houses are mainly located on low land covering C1kcikKuyusu, KadinKuyusu, Grankçay and Bagbası.Vineyard houses rest in wide gardens close to the Antalya-Burdur highway approximately 3-4 kilometers from the borough's center. Generally, people used to move into Vineyard houses in May. In the beginning of autumn after vine-harvesting and boiling grapes to prepare for the winter, they returned to their homes in the more populated borough center. Vine cultivation has lost importance beginning in the early 1960s with apple cultivation taking its place. With this, people slowly started to vacate vineyard houses and gardens used for the plantation of grains. Later, with a transition to a nuclear family from a patriarchal structure, the tradition of moving into vineyard houses during the summer 
disappeared. At the dawn of the 21 st century, almost all Vineyard houses became unusable.In this study, Vineyard house settlements under no official protection status and containing regional architecture items were examined within an ecological criteria framework. Structures were constructed according to regional conditions and were able to meet desired ecological conditions of planning rudiments and material structure. These conditions were not met with reinforced concrete structures built today under the same conditions. Sample reliefs were taken from vineyard houses and were usually quite similar. We expect that our study will spotlight vineyard houses in the literature regarding material, settlement texture, and architectural planning. Additionally, we hope that this work will foster new designs.

\section{Material and Methods}

Bucak is located in the Western Mediterranean and is a borough subordinated to the Burdur province. It lies between 30-31 degrees east and 35-38 degrees north with a surface area of $1436 \mathrm{~km}^{2}$. The borough's center is on the Burdur - Antalya highway, 44 kilometers from the Burdur Province and 80 kilometers away from the Antalya Province. The borough's center exists as a base between two sides of a valley extending towards the lowland, dividing its geographical structure into two sections. Vineyard house settlements and associated agricultural lands are located in the lowland section west of the Burdur-Antalya highway. The borough's urban settlement lies in the East among mountainous and forests. The borough's is elevated about 850 meters above sea level (Bucak District Governorship, 2013) (Fig 1). The borough experiences a transitionary climate between Mediterranean and Central Anatolian climates. While temperature drops to $-5^{\circ} \mathrm{C}$ during winter months, the average high temperature during summer months is $40^{\circ} \mathrm{C}$. Rainfall is predominant during winter months and in the beginning of spring. The annual average temperature is $15^{\circ} \mathrm{C}$ (MGM, 2012).

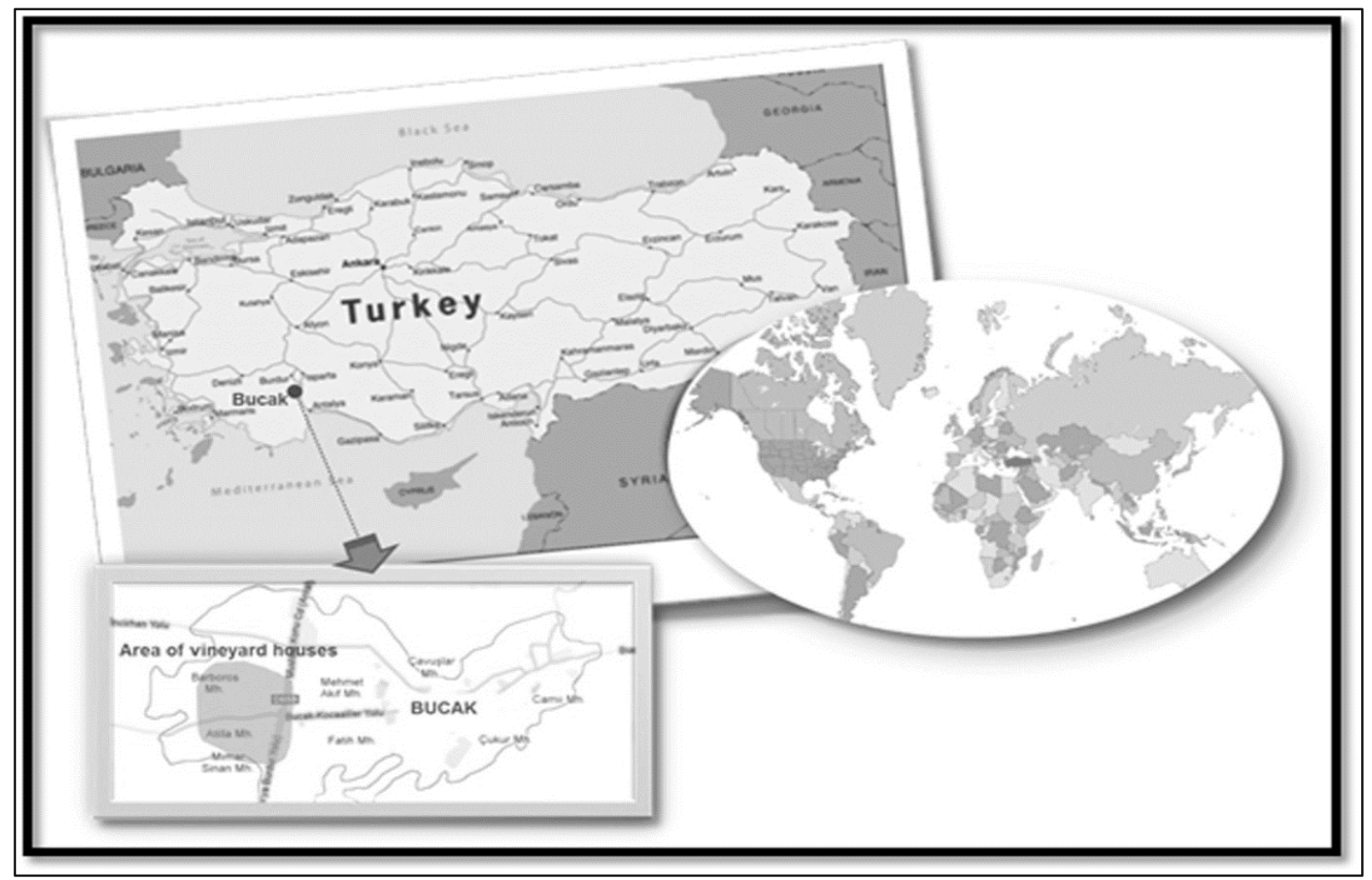

Fig 1. Bucak Borough, vineyard houses region settlement status (Original, 2013) 
History of Bucak Borough and its surroundings originates from 1900 B.C with the first settlement most likely being Cremna. Throughout its history, Bucak Borough's surroundings have been dominated by many cultures. From historical ruins and burial mounds, the Psydgians, Phrygians, Selechosians, Greeks, Romans, Byzantines, Seljukians and Ottomans have controlled the region (Bucak District Governorship, 2013). Our research aims to better understand vineyard houses' plan types, which has been examined in the framework of ecological criteria encompassing regional architecture, settlement structure, building form, place organization, and material choice (Krusche et al., 1982; Tonuk, 2001; Filik, 2004; Gultekin and MutluDanaci, 2011).

\section{Assessment of vineyard houses using ecological criteria}

When we examine Bucak vineyard house settlement structure, we consider the agricultural lands on which they reside. Topographically, the slope of this land is minimal: between $0-10 \%$. Houses are located on plots of surface areas between $3000-7000 \mathrm{~m}^{2}$. This region was zoned for housing beginning in the 1960s, with new residences following an arrangement of $30 \%$ base area and $60 \%$ floor area on $400-600 \mathrm{~m}^{2}$ plots (Bucak Municipality, 2013). This ultimately caused destruction of vineyards in gardens of Vineyard houses through altering or demolishing existing structures (Fig 2). As seen in Fig 2, twenty-one standing Vineyard houses are worn completely and abandoned. Vineyard houses have two flats with an average base area size of 60-70 $\mathrm{m}^{2}$. Most vineyard houses are along the "Grankcay" creek. A settlement area parallel to the creek has grown and branched. Vineyard houses have gardens surrounded by stone masonry walls $50-60 \mathrm{~cm}$ high, high-crowned wooden garden gates known as "huge gates," and stables close the garden entry gates.

Structures were built on the west end of the land due to the burning western sun's detriment tosummer agriculture. Almonds trees (Prunus dulcis) were planted along the western border of land and east of houses to create shade for people and plants.

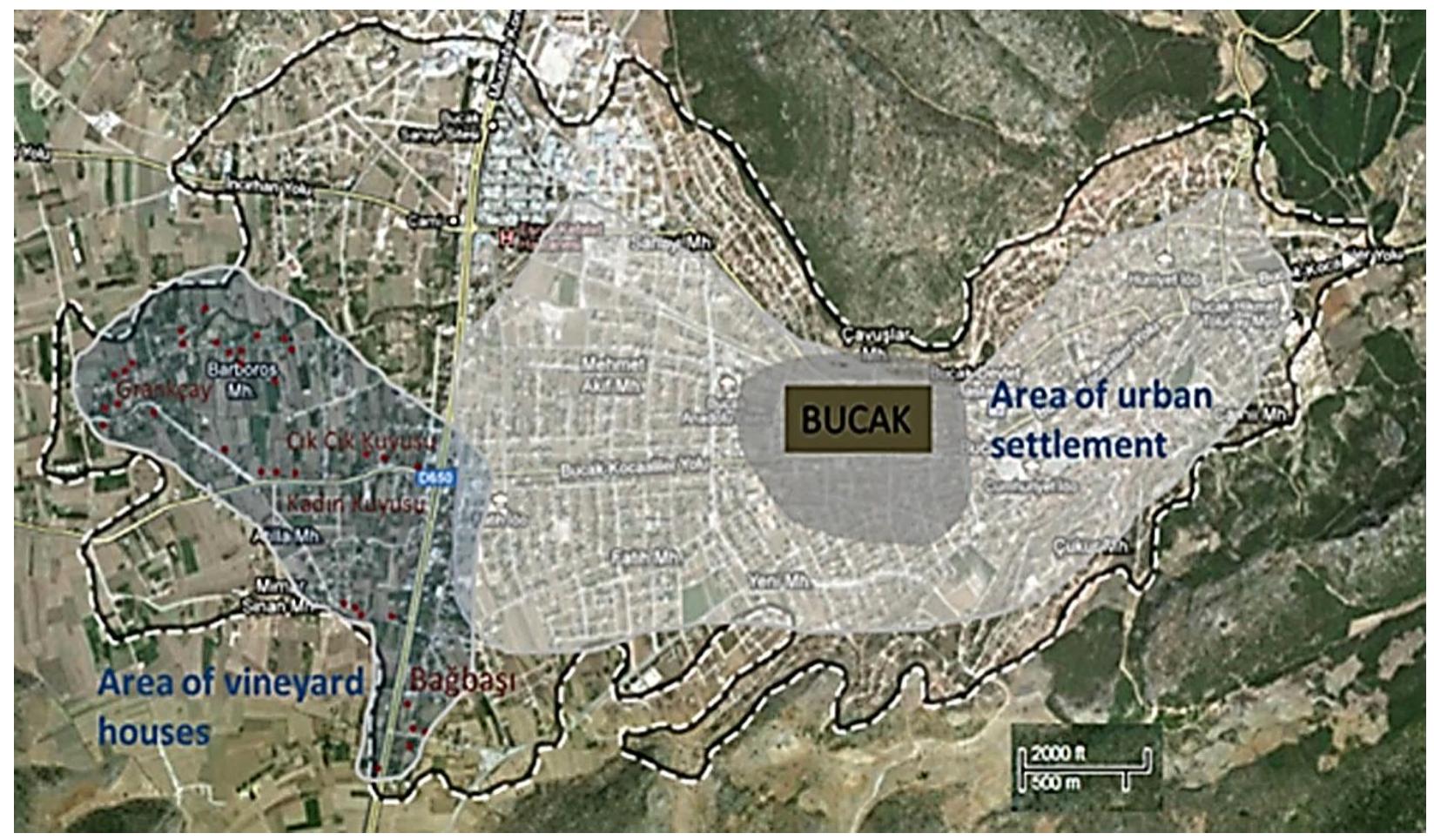

Figure 2. Current vineyard houses in Bucak Borough (Original, 2013) 
A cooker was placed in the west garden under shade, typically for bread and meals during morning hours. Houses were located in gardens close to the roads to ease carrying of products. In general, there are vineyards in the backyard, a mulberry tree (Morus rubra) on the south-east corner, and fruit trees such as cherry (Prunus savium) and prune (Prunus salicina) on the east side of the property. These trees can grow in the regional climate and soil. Additionally, there are elaeagnus (Elaeagnus angustifolia) trees on the northern border, considerably far from the structure. There are eastern vegetable gardens close to the house (Fig 3).

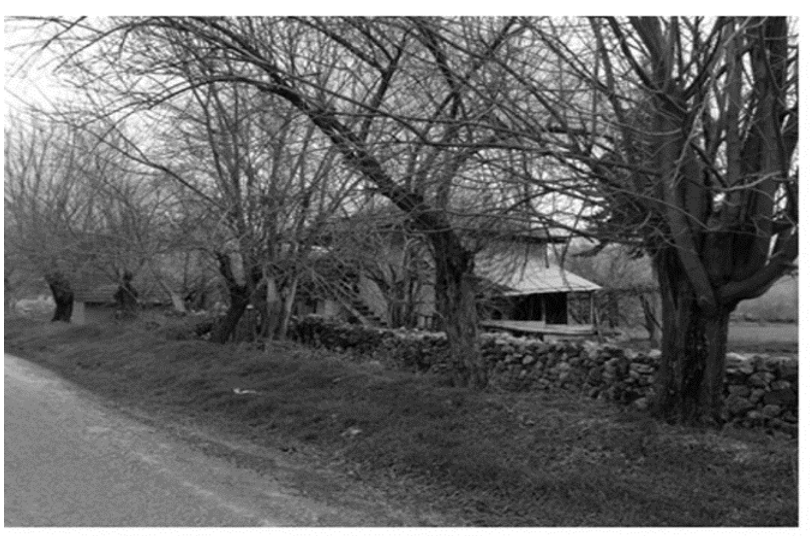

a

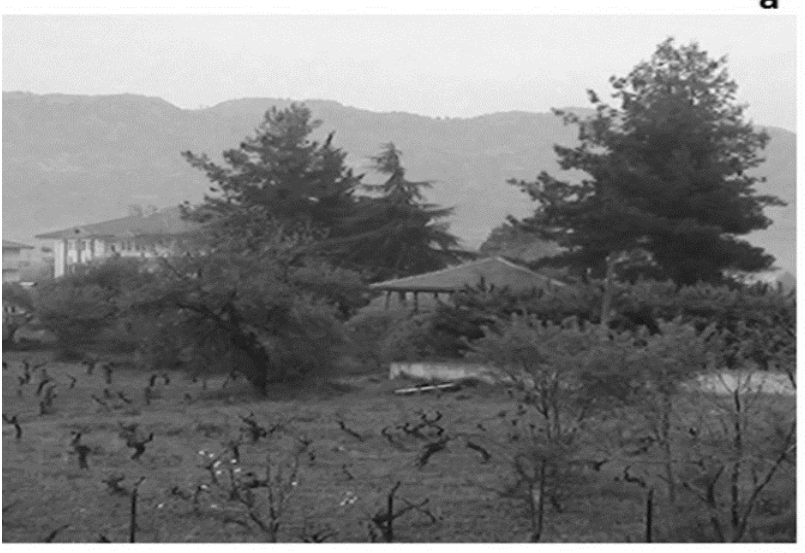

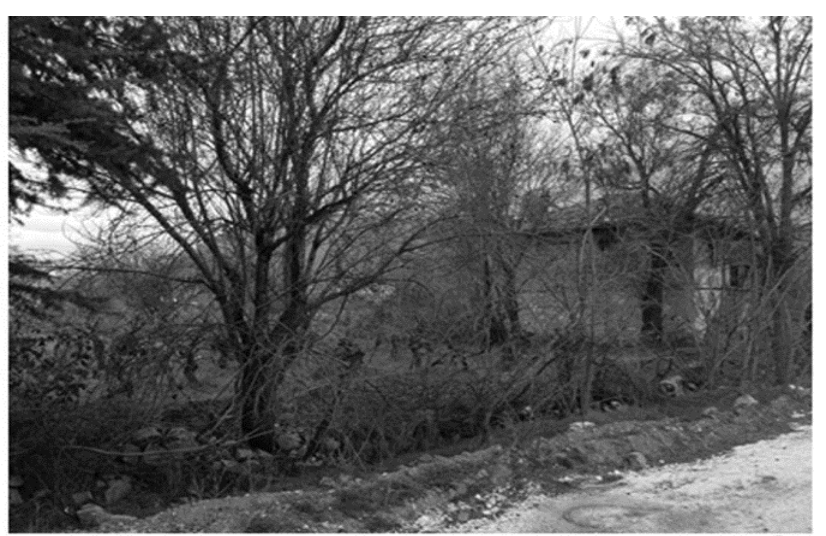

b

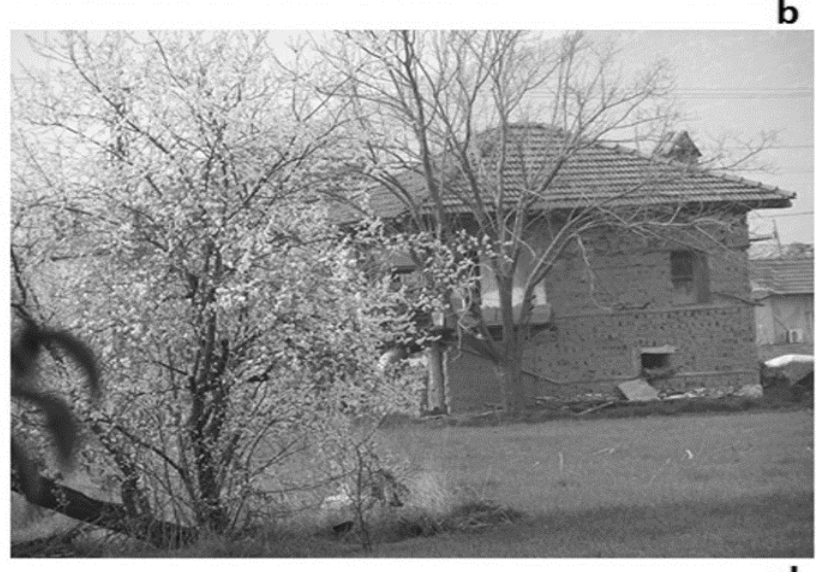

d

Figure 3. Samples from vineyard houses and their gardens (Original, 2013)

Cultivated agriculture lands are located on the western parts of the lowland. Roads are wide enough for two vehicles and are shaded by tress on the land border. The region also consists of wide meadow prairies called "threshing fields," where people living in the region store agricultural products like grain and straw. Vineyard houses have an overall square form. They have balconies with fixed seats on the sides called "ş̧ahni." These are 3 meters wide and 7-8 meters long and are situated in the north-south direction. Elevation differences of $15-20 \mathrm{~cm}$ provide the division of the terrace into functional places. The north and south sides of this wide east balcony are open take advantage of the wind during hot summer days. From this terrace, it is possible to reach one or two rooms on the west side. Structures are covered with a set wooden roof (also called "şahni") to cover the balcony. The building's east side is half open to both downstairs and upstairs, and there are one or two rooms on both in the west. The ceiling heights of the floor and top levels are $240 \mathrm{~cm}$ and $210 \mathrm{~cm}$, respectively. Fireplaces warm the upstairs room for autumn. Since ground floor rooms were generally 
used as the depot for materials or products. Top floor rooms have 80 by $110 \mathrm{~cm}$ shutters. The shutter opens to the inside and food was placed in a $50-70 \mathrm{~cm}$ cavity generated by a stone or mud-brick wall to remain cool in the evening. Wooden shutters were kept closed during the day, keeping the room cool during hot summer days and warm during their first evenings of autumn. The depot room window opens to the north to provide cooler room conditions (Fig 4). We examined Bucak Borough Vineyard houses in terms of place organization. The downstairs terrace is reachable by a path named 'yolgecer,' begins at the garden gate and passes from the stable and stone watering troughs. It is two meters wide and covered by plants. Grapevine Houses have an external hall plan type and upstairs is reached by stairs at one corner of the terrace. A wooden cover device on the stairs is closed throughout the night and opened during the day to provide safety. While there are one or two rooms in the west facades of houses, the east facades are completely allocated to a half-open living area with balconies "sahni" (Fig. 5a). A lavatory exists in one section of the sitting places, serving as a banister. Rooms have flexibility as places of sleeping, sitting, dining, and cooking. A cooker (fireplace) (Fig. 5b) is used for cooking and heating during the cool evenings of early autumn months. Shelves are made within the cavities surrounding the cooker and wooden shelves are called "seren" (Fig. 5c). In one or two rooms, there are wooden cabinets for bedding called Yüklük (Fig. 5d) 60-70 cm wide. Cabinet covers are generally curtain fabric. Bathing occurs in these cabinets or on a downstairs depot corner. The WC is a wooden structure in the backyard 15-20 meters from the house (Fig 5).
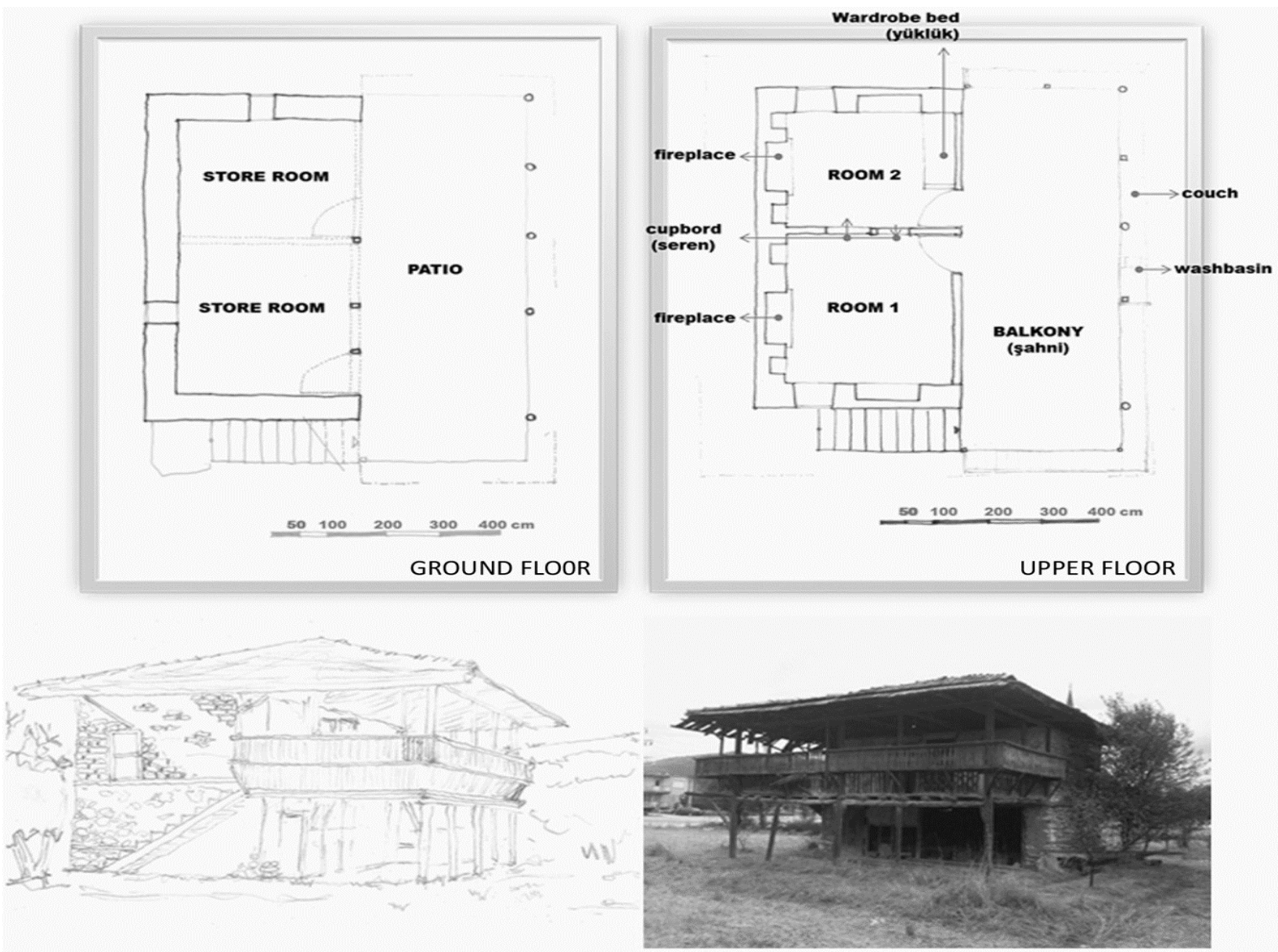

Figure 4. Vineyard house relief samples (Original 2013) 


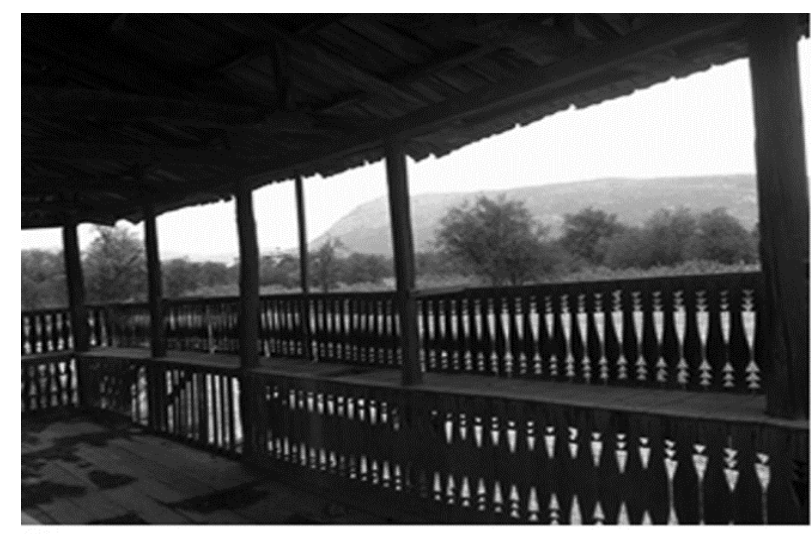

a

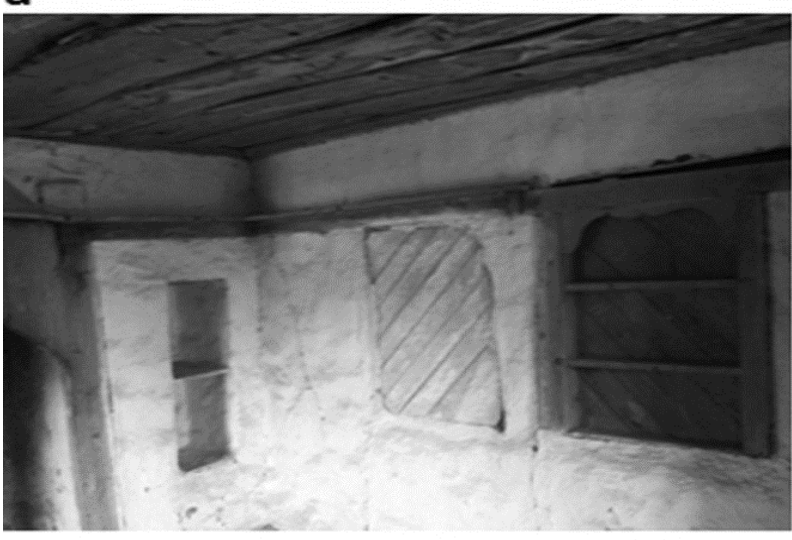

C

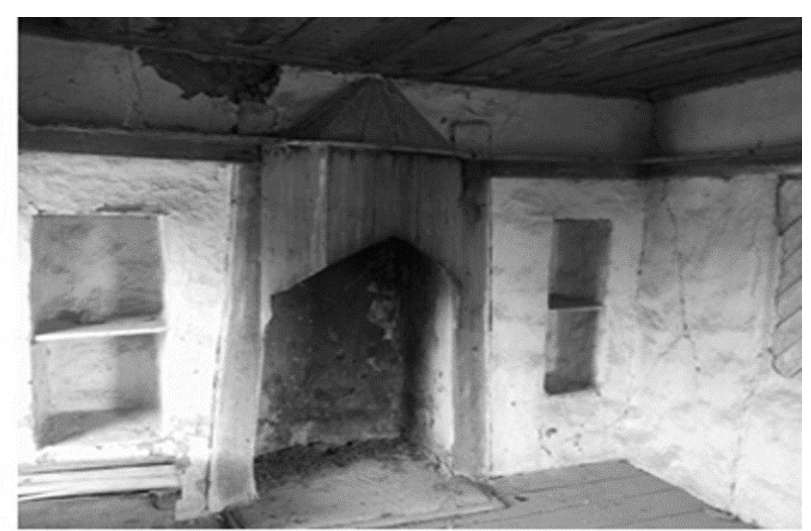

b

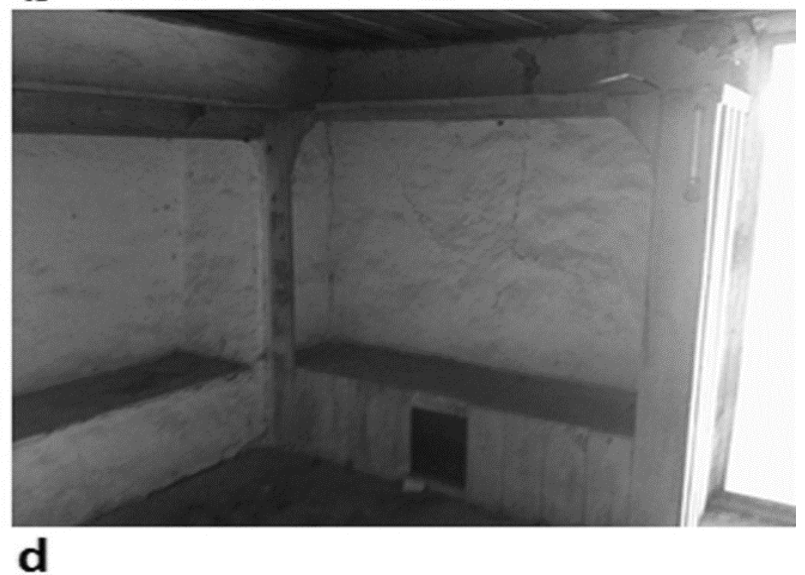

Fig 5. Views from Bucak Borough vineyard houses (Original, 2013)

The downstairs rooms of the vineyard house are designed as depots or stables, while living areas are selectively upstairs. In more recent periods of some houses, a cooker and small kitchen was added to the terrace downstairs, sleeping remained upstairs, and guests were entertained in wide "sahni". Ecological building materials were chosen with complete respect for environment and nature. Although some vineyard houses were vacated and destroyed, the wooden and stone materials were reusable. Land on which the houses once stood could also be currently used due to little construction waste. Dry masonry walls were also build in compliance with nature in the senses of ecology and aesthetic. The house walls are stone and the stairs balcony called a "sahni", are both wooden. These stone walls are approximately 50-70 $\mathrm{cm}$ thick and provide insulation. Stone walls were always chosen for ground floors and stone or mudbrick was the building material for upstairs. External walls were typically $50-70 \mathrm{~cm}$ thick, and divider walls separating rooms and walls on the eastern side of sahni were $10-15 \mathrm{~cm}$ thick and composed of wood with soil plaster. The floor was also plastered with another type of soil plaster. Since soil material does not insulate both hot and cold, it is possible to create a cool environment during summer months. Depot floors were composed of rammed earth, and later were reinforced with concrete material. The terrace was constructed with either cedarwood (Cedrus libani) or juniper (Juniperus communis), the roof tile was in Turkish style, and the ceiling was covered with wood. Roof space was covered with rammed earth of $10-15 \mathrm{~cm}$ thickness, also providing insulation. The narrow walkway beginning from the garden entrance gate to the house, and again from the house to the WC was left natural with rammed earth and grass. When people move to vineyard houses during the last months of the spring season, the meadow is green and the grass is dry, forming a suitable ground for circulation. Landscape is an important indication for the quality of life and is also a vital part of daily life (Council of Europe 
2000; Official Gazette, 2003). There thus exists a need identify and understand cultural landscapes that have decorated the past and still influence the present. While Agnoletti (2006) emphasizes a requirement for protecting cultural landscapes, Bridgewater and Bridgewater (2004). have discussed a need to sustain these landscapes. Dyer (2006) has indicated a necessity of viewing cultural landscapes and architecture that fills them and their inhabitants as a unit. Anna-Maria (2009) has examined regional settlements with passive design principles based on climatic and environmental characteristics. Sami and Ozdemir (2011) have compared regional architecture in Harran with contemporary structures, with emphasis climate, landscape, and sociology. Fuentes et al (2010) searched for reuse potential by examining vacated regional agriculture structures. Vural et al (2007) have examined regional residence architecture through structure proposals. Zavadskas and Antucheviciene (2007) assessed vacated and unused structures in rural landscapes with physical and socio-cultural criteria.Vineyard houses were uniquely constructed and developed in compliance with ecological criteria and regional architecture within indigenous climate and landscape. In our study, Vineyard house data is assessed together with landscape to provide protection of design principles, materials, structuring technique, and functionality. Vural et al (2007) and Gunce et al (2008) present structure proposals according to regional design principles only with current materials and structuring techniques. To maintain the integrity of architecture with landscape, protection of original structure materials is imperative. In order to construct new houses, existing structure types in the region must be determined, and future construction must include appropriate construction materials, technique, and placement.

\section{Conclusion}

Vineyard houses that we examined were vacated and unused. With a demand, it is possible to construct Vineyard houses with original materials by having original plan features. With this, temporary accommodation for summer house vacationists coming to Bucak Borough is possible.
Developing and promoting rural tourism can protect cultural landscapes as a whole. Bucak Borough is closer than many boroughs of Antalya. By being an alternative to coastal tourism in Antalya, the borough has rural tourism potential with pleasant climatic characteristics, a traditional way of living, and architectural splendor. Using vineyard houses as traditional housing models, collecting grapes from a vine-harvest, and displaying how grape molasses are made are only a few alternatives to promote rural tourism. Agriculture is a cornerstone of cultural and natural characteristics of an area. Natural landscape characteristics like climate and topography also shape architecture. Understand architecture in the context of landscape is important to keep both alive as a whole.

\section{References}

Agnoletti, M., 2007. Introduction: framing the issue - A transdisciplinary reflection on cultural Landscapes. In M. Agnoletti (eds.), Conservation of Cultural Landscapes, CABI Publishing.

Anna-Maria, V., 2009. Evaluation of a sustainable Greek vernacular settlement and its landscape: Architectural typology and building physics. Building and Environment, 44: 1095-1106.

Bowyer, J., 1980. Vernacular Building Conservation, The Architectural Press, London, 184.

Bridgewater, P. and Bridgewater, C., 2004. Is there a future for cultural landscape? In R.H.G. Jongman (eds.), The New Dimensions of the European Landscape, Springer, Dordrecht, pp: 193-200.

Bucak District Governorship, 2013. Archives of Bucak District Governorship, www.bucak.bel.tr., arrived date: Ekim 2013.

Council of Europe, 2000. The European Landscape Convention (STE $n^{\circ} 176$ ), www.coe.int.

Dyer, C., 2006. Vernacular architecture and landscape history: The legacy of the rebuilding of rural England and the making of the English landscape. Vernacular Architecture, 37: 24-32.

Filik, O.A., 2004. Ecological Design and Review of Ecological Design Samples in Turkey, Ph.D. Thesis submitted to Yildiz Technical University, İstanbul.

Fuentes, J.M. and Gallego, E. and Garcia, A.I. and Ayuga, F., 2010, New uses for old traditional farm buildings: The case of the underground wine cellars in Spain. Land Use Policy, Elsevier 27: 738-748. 
Gultekin, R.E. and MutluDanaci, H., 2011. Ecological problems of restorated traditional settlements: A case study in Kaleici, Antalya. Journal of the World of Turks, Almanya, 3(3): 49-58.

Gunce, Z. and Erturk, Z. and Erturk, S., 2003. Questioning the "prototype dwellings" in the framework of Cyprus traditional architecture. Building and Environment, Elsevier, 43: 823833.

Krusche, P. and Krusche, M. and Althaus, D. and Gabriel, I., 1982. Ökologisches Bauen, Bauverlag GmbH, Wiesbaden, Berlin, 360.

MGM, 2012. Antalya Meteoroloji Genel Mudurlugu Arsivi, (Archive of Antalya Governmental Meteorological Office).

Mutlu Danaci, H., 2012. Vernacular architecture and cultural landscape analysis: Antalya Elmali Example, Ph.D. Thesis submitted to Akdeniz University, Turkey.

Official Gazette, 2003. Avrupa Peyzaj Sozlesmesi 'nin Turkiye' de OnaylanmasininUygun Bulunduguna Dair Kanun (Legislative decree about doing in Turkey in European Landscape Convention) 10.06.2003, no: 4881.
Oliver, P., 2003. Dwellings: The Vernacular House World Wide, Phaidon Press Limited, London.

Original, 2013. Archive of Hacer MutluDanacl about study of Bucak vineyard houses.

Sami, K. and Ozdemir, I., 2011. The vernacular houses of Harran and cultural heritage Turkey. International Journal of Academic Research, 3(3): 148-157.

Tonuk, S, 2001. Ecology in Building Design, Yildiz Technical University Press, 133.

Vellinga, M. and Oliver, P. and Bridge, A., 2007. Atlas of Vernacular Architecture of the World, Routledge, USA, 150.

Vural,, N. and Vural, S and Engin, N. and Sumerkan, M. R., 2007. Eastern Black Sea Region - A sample of modular design in the vernacular architecture, Building and Environment, 42: 2746-2761.

Zavadskas, E. K. and Antucheviciene, J., 2007. Multiple criteria evaluation of rural building's regeneration alternatives, Building and Environment, Elsevier, 42: 436-451. 